\title{
OPEN Socioeconomic variation of multimorbidity in Colombian older adults
}

\begin{abstract}
Silvia Marcela Ballesteros ${ }^{1 凶}$, José Moreno-Montoya ${ }^{1}$, Wilhelmus Johannes Andreas Grooten ${ }^{2,3}$, Pedro Barrera-López ${ }^{1}$ \& José A. De la Hoz-Valle ${ }^{1}$

Multimorbidity (MM) prevalence among older adults is increasing worldwide. Variations regarding the socioeconomic characteristics of the individuals and their context have been described, mostly in high-income settings. However, further research is needed to understand the effect of the coexistence of infectious diseases along with socioeconomic factors regarding MM. This study aims to examine the variation of MM regarding infectious diseases mortality after adjusting for socioeconomic factors. A cross-sectional multilevel study with a nationally representative sample of 17,571 Colombian adults of 60 years of age or older was conducted. Individual socioeconomic, demographic, childhood and health related characteristics, as well as group level variables (multidimensional poverty index and infectious diseases mortality rate) were analyzed. A two-level stepwise structural equation model was used to simultaneously adjust for the individual and contextual effects. Multimorbidity prevalence was $62.3 \%$ (95\% Cl 61.7-62.9). In the multilevel adjusted models, age, female sex, having functional limitations, non-white ethnicity, high body mass index, higher income, physical inactivity and living in urban areas were associated with multimorbidity among the sample for this study. The median odds ratio for multidimensional poverty was $1.18(1.16-1.19 ; \mathrm{p}=0.008)$ and for infectious diseases was 1.25 (1.22-1.28; $p=0.014)$. This paper demonstrates that MM varies regarding the mortality of infectious diseases and shows a strong association between MM and poverty in a low-middle income country. Differences in the factors involved in the etiology of multimorbidity are expected among wealthy and poor countries regarding availability and prioritization of health services.
\end{abstract}

Multimorbidity (MM), considered as the co-existence of two or more chronic conditions $\mathrm{s}^{1,2}$ has been estimated to affect approximately 50 million people in Europe ${ }^{3}$ and one third of adults in Latin American countries ${ }^{4}$. In Colombia, among the registries of health services provided between 2012 and 2016, almost 6 million correspond to patients living with multimorbidity per year ${ }^{5}$. This figure is expected to increase since the prevalence of $\mathrm{MM}$ pursue advances along with the demographic transition ${ }^{6}$. Estimates in Europe report figures rising from $11 \%$ in adults aged $25-44$ years to $65 \%$ for those aged $65-84$ years, and up to $82 \%$ in those 85 years and older ${ }^{7}$. A similar trend is observed for Colombia with figures ranging from $33.1 \%$ in adults to $51.3 \%$ in people aged 60 or older $^{5}$. Moreover, MM has been associated with poor health outcomes including functional decline ${ }^{8-10}$, excess of mortality ${ }^{11,12}$, decrease in quality of life levels ${ }^{10}$ and high economic costs of care due to increased hospitalization rates $^{13}$ and polypharmacy ${ }^{14}$.

Variations in the prevalence of MM have also been associated with demographic and socioeconomic characteristics, being higher in women, single, widowed or divorced ${ }^{15}$, persons of lower socioeconomic levels and in those living in disadvantage settings ${ }^{1,10,16}$. Socioeconomic factors such as low-educational status ${ }^{16,17}$, childhood adversity ${ }^{18}$, and reduced lifetime earnings are related to an increased risk of developing MM in late life ${ }^{19}$. Likewise, previous research have indicated that MM rates are higher among population groups with greater difficulties accessing to drinking-water and energy for lighting sources ${ }^{20}$, as well as in areas with higher rates of unemployment and household overcrowding ${ }^{21,22}$. In particular, the prevalence of MM has been reported to be almost twice as high in areas of high socioeconomic deprivation (11.0\%, 95\% CI 10.9-11.2), compared to more affluent areas $(5.9 \%, 5.8-6.0)^{21}$.

${ }^{1}$ Clinical Studies and Clinical Epidemiology Division, Fundación Santa Fe de Bogotá, Calle 119 A 7-49, Bogotá, Colombia. ${ }^{2}$ Department of Neurobiology, Care Sciences and Society, Division of Physical Therapy, Karolinska Institutet, 14183 Huddinge, Sweden. ${ }^{3}$ Women's Health and Allied Health Professionals Theme, Medical unit Occupational Therapy and Physiotherapy, Karolinska University Hospital, 17177 Stockholm, Sweden. ${ }^{\square}$ email: smballesterosr@gmail.com 
As it has been widely recognized, poor populations usually face the simultaneous effects of both chronic and infectious diseases. Similar to the association of chronic conditions with socioeconomic deprivation, those living in poorer communities are also more vulnerable to communicable diseases than the most affluent ones ${ }^{23}$, and these effects could be more serious in older adults due to the immunosenescence that make this population more susceptible to infections ${ }^{24}$. As long as the effect of the coexistence of infectious diseases along with socioeconomic factors regarding MM is not recognized, particular measures of prevention or even health needs could be omitted in regions where communicable diseases are endemic. Therefore, in this paper we examined the variation of MM regarding infectious diseases mortality after adjusting for the effects of socioeconomic factors.

\section{Methods}

Study design. A cross-sectional multilevel study was developed using secondary data from the Colombian population-based survey Health, Wellbeing and Aging (Salud, Bienestar y Envejecimiento-SABE), carried out in 2015. The SABE study included 23,694 individuals aged over 60 years living in urban and rural areas of the 32 Colombian departments (i.e., states). Participants were selected by a probabilistic, multistage and stratified sampling design. Data collection was completed using in-person surveys. For the analyses, a sample of 17,571 participants was used once records with missing information were excluded. Detailed information about the SABE study and the sampling method can be found elsewhere ${ }^{25}$.

Variables. For the analysis "Multimorbidity" was considered the dependent variable, defined as the coexistence of two or more non-communicable diseases: diabetes, hypertension, cancer, lung disease (chronic obstructive pulmonary disease, asthma, bronchitis or emphysema), heart disease, stroke, joint diseases (arthritis, rheumatism or osteoarthritis), osteoporosis, depressive symptoms and other mental illnesses (mental or psychiatric problem). Except for depression, which was assessed with the Short Form of the Geriatric Depression Scale ${ }^{26}$, all morbidities were self-reported. A score of 6 or more was used as indicator of depression in the population ${ }^{26,27}$.

The independent variables of interest were both at individual and at group level. At individual level, the following categorical and continuous sociodemographic characteristics were used: Sex (female/male (reference category)), Age (continuous), Marital status (single, widowed or divorced/married or living with a partner (ref)), Ethnicity (non-white/white (ref)), Income (mean income less than $\$ 7.83 /$ day/income of $\$ 7.83 /$ day/more than $\$ 7.83 /$ day (ref)), Educational level (secondary or lower level/higher level (ref)), Victim of armed displacement, defined as ever been displaced by armed conflict or violence (yes/no (ref)), Area of residence (rural/urban (ref)). Health and lifestyle-related variables included were Functional limitation defined as having a Barthel score of $<100^{28}$ (yes/no (ref)), Body Mass Index (BMI) (low $(<22) /$ overweight/obesity $(>27)$ /normal weight $(22-27)$ $($ ref $))^{29}$, Physical inactivity or a low level score of physical activity in the short-form International Physical Activity Questionnaire-IPAQ-SF ${ }^{30}$ (yes/no (ref)) and Smoking (current or former smoker/nonsmoker (ref)). Childhood-related factors were also included as Self-perceived childhood economic situation (fair/poor/good (ref)) and Self-perceived childhood health status (poor or fair/good (ref)).

At state-level, we used the prevalence of the multidimensionally poor ${ }^{31}$ for $2018^{32}$ and infectious diseases mortality rate for $2016^{33}$. To evaluate multidimensional poverty (MP), 5 dimensions with 15 indicators are measured, including: education, childhood and youth conditions (school attendance, childcare services), employment (informality, long-term unemployment), health (access, insurance), access to public utilities (water source, sewer system) and housing conditions (floors and walls material, overcrowding) ${ }^{31}$. Those deprived in 5 or more indicators are considered as multidimensionally poor ${ }^{34}$.

Statistical analysis. Descriptive analysis of the individual characteristics was based on the absolute and relative frequencies with 95\% confidence intervals (95\% CI) for categorical variables, and measures of central tendency and dispersion (mean and standard deviation (SD)) for quantitative variables. To identify differences between baseline characteristics, independent $\mathrm{X}^{2}$ test and $t$-test analyses were developed for categorical and continuous variables respectively. Variables with p-values below $25 \%$ were considered for the adjusted models. A first one-level logistic model was used to evaluate the associations between the individual variables with $\mathrm{MM}$, and significant variables $(\mathrm{p}<0.05)$ were included in a multilevel stepwise backward model. To evaluate the variability of MM prevalence across states, the median OR (MOR) ${ }^{35}$ was calculated. Correlation was evaluated between MM and MP, between MM and infectious diseases mortality, and between infectious diseases mortality and MP, using Pearson correlation coefficients. A two-level structural equation model (SEM) was used to assess the association among individual and contextual variables with MM. The effect of state-level variables that were not measured, due to secondary data availability, was incorporated into the model through a latent variable. MP, BMI, physical activity and functionality were considered correlated in the model ${ }^{36}$. Sample weights were used in all the analyses.

Ethics declarations. All methods in the present study were carried out in accordance with relevant guidelines and regulations. Ethics approval was granted by the Institutional Committee of Human Ethics of the Fundación Santa Fe de Bogotá Hospital. The approval ID is CCEI-11861-2020. As clinical data was used, participants provided written informed consent before enrolling in the SABE study ${ }^{25}$.

\section{Results}

The overall prevalence of MM in the Colombian sample who were 60 years of age or older was $62.3 \%$ (95\% CI $61.7-62.9 \%)$, the average age was 70.8 years $(\mathrm{SD}=8.2)$ and $57.3 \%(56.7-58.0 \%)$ were women. Most frequent diseases in the population were depression, 56.9\% (56.2-57.6), hypertension, 53.9\% (53.2-54.6), and joint disease, 


\begin{tabular}{|c|c|c|c|c|c|c|c|c|c|c|}
\hline & Diabetes & Cancer & Lung disease & Heart disease & Stroke & Joint disease & Mental illness & Depression & Osteoporosis & Total $(95 \%$ CI) \\
\hline Hypertension & 12.4 & 2.7 & 6.4 & 10.8 & 3.5 & 16.3 & 5.6 & 25.5 & 7.2 & $53.9(53.2-54-6)$ \\
\hline Diabetes & & 0.8 & 2.1 & 3.5 & 1.1 & 5.1 & 1.9 & 7.8 & 2.4 & $16.4(15.9-17.0)$ \\
\hline Cancer & & & \begin{tabular}{|l|}
0.8 \\
\end{tabular} & 0.9 & 0.3 & 1.5 & 0.5 & 2.2 & 0.8 & $4.4(4.1-4.7)$ \\
\hline Lung disease & & & & 2.8 & 0.7 & 3.8 & 1.5 & 5.0 & 2.1 & $10.2(9.8-10.6)$ \\
\hline Heart disease & & & & & 1.5 & 4.7 & 2.1 & 6.4 & 2.5 & $13.6(13.1-14.1)$ \\
\hline Stroke & & & & & & 1.3 & 0.8 & 2.4 & 0.6 & $4.6(4.3-4.9)$ \\
\hline Joint disease & & & & & & & 3.5 & 12.4 & 6.9 & $26.0(25.3-26.6)$ \\
\hline Mental illness & & & & & & & & 4.1 & 1.7 & $8.5(8.1-8.9)$ \\
\hline Depression & & & & & & & & & 5.8 & $56.9(56.2-57.6)$ \\
\hline Osteoporosis & & & & & & & & & & $11.5(11.1-12.0)$ \\
\hline
\end{tabular}

Table 1. Population proportion in every comorbidities combination.

26.0\% (25.3-26.6). Those living with two or more conditions suffered mainly of hypertension and depression (25.5\%), hypertension and joint disease (16.3\%), and hypertension and diabetes (12.5\%) (Table 1).

Crude comparisons at individual-level showed that all variables were significantly associated with MM except for educational status and smoking (Table 2). Once adjusted, the effects that remained significant were age, sex, having functional limitations, body mass index (BMI), income, physical inactivity, non-white ethnicity and living in urban areas (Table 3).

At state-level, the prevalence of MM varied between $42.6 \%$ (36.6-48.9) and 74.1\% (69.2-78.5), where the ages ranged from 60 to 93 years $($ mean $=69.0 ; \mathrm{SD}=7.7)$ and from 60 to 96 years $($ mean $=69.3 ; \mathrm{SD}=7.5)$, respectively. MP varied from 4.4 to 65.0 ( mean $=28.2$; $S D=15.1$ ), where ages ranged from 60 to 101 years $($ mean $=70.8$; $\mathrm{SD}=8.2)$ and from 60 to 90 years (mean $=68.7 ; \mathrm{SD}=6.3)$, respectively. Infectious diseases mortality rate varied from $12.6 / 100,000$ to $51.0 / 100,000($ mean $=35.9 / 100,000 ; S D=1.7)$ (Table 4), and the ages ranged from 60 to 96 years $($ mean $=69.3 ; \mathrm{SD}=7.5)$ and from 60 to 90 years $($ mean $=68.7 ; \mathrm{SD}=6.3)$. Correlation between MM prevalence and MP was of $-0.80(\mathrm{p}<0.001)$, between MM and infectious diseases mortality of $-0.40(\mathrm{p}=0.022)$, and between infectious diseases mortality and MP of $0.18(\mathrm{p}=0.320)$.

Adjusted analyses indicated a significant inter-state variability. The MOR for MP was 1.18 (1.16-1.19; $\mathrm{p}=0.008)$ and for infectious diseases was $1.25(1.22-1.28 ; \mathrm{p}=0.014)$. The association between MP and MM was also mediated by physical inactivity $(\mathrm{p}=0.001)$, BMI $(\mathrm{p}=0.002)$ and functional limitation $(\mathrm{p}=0.001)$. All individual variables were directly associated with MM in the model (Fig. 1).

\section{Discussion}

This study found a $63 \%$ prevalence of multimorbidity among Colombian older adults when considering a list of ten chronic conditions and a cut-off point of 2 or more concurrent morbidities for its definition, including diabetes, hypertension, cancer, lung disease, heart disease, stroke, joint disease, osteoporosis, depressive symptoms and other mental illnesses. Compared to findings from other authors, this corresponds to earlier studies in developing countries such as Brazil and Argentina, in which the prevalence of MM among older adults has been reported to be of $66.3 \%{ }^{37}$ and $60.6 \%{ }^{38}$, respectively. In this study, around $30 \%$ of those living with MM had poor functional status, which reinforces the need for preventive, coordinated and non-fragmented care ${ }^{21}$.

In this study MM prevalence increases with age, is higher in women and in individuals with high body mass index as reported before ${ }^{6,19}$. Our results also showed that in the states with higher infectious diseases mortality rate, MM was less likely to be reported. In deprived contexts, where infectious diseases are more prevalent, decision makers are compelled to assign significant portions of resources to the attention and diagnosis of these diseases displacing the care of chronic conditions, in particular $\mathrm{MM}^{39}$.

In contrast to previous studies our results indicate lower levels of MM in people living in middle/high income or less deprived settings. Barnett et al. ${ }^{21}$ and Salisbury et al. ${ }^{22}$, in a Scottish and English population, respectively, found that people living in more deprived settings were more likely to be living with MM. These dissimilarities could derive from methodological matters including the use of clinical records and a more specific list of morbidities for the definition of MM in these studies ${ }^{21,22}$. Also, a better opportunity to be diagnosed or have a medical evaluation in more affluent settings could partly explain them; in fact, in less prosperous contexts, limited availability of resources is associated with a lower rate in diagnosis of non-communicable diseases ${ }^{40-42}$.

Furthermore, the use of self-assessments instead of using medical records, could have led to a difficulty to accurately recall diagnosed chronic diseases. In addition, ongoing treatment might be higher in more affluent populations with better access to medical care which can improve the diagnosis self-reports ${ }^{40}$.

Living in a rural residence, being non-white ethnicity and low household income, all of which have been related with deprivation, were also associated with lower risk of reporting multiple chronic conditions. Similar findings have been found by previous research ${ }^{40,43}$, and are also related with the accessibility to public and private services. Therefore, our results might reflect an under-reported prevalence of MM in poor regions and populations due to difficulties in the access to health services and limited resource availability for adequate diagnosis.

Our findings contrast mainly with studies conducted in high-income countries. However, comparisons among national-level figures must consider differences among access to healthcare, services coverages and deprivation 


\begin{tabular}{|c|c|c|c|c|c|c|c|c|}
\hline \multirow[b]{2}{*}{ Variable } & \multicolumn{2}{|c|}{ Total $(n=17,571)$} & \multicolumn{2}{|c|}{\begin{tabular}{|l|} 
With \\
Multimorbidity \\
$(\mathrm{n}=10,615)$
\end{tabular}} & \multicolumn{2}{|c|}{\begin{tabular}{|l|} 
Without \\
Multimorbidity \\
(n=6956)
\end{tabular}} & \multirow[b]{2}{*}{ OR (CI 95\%) } & \multirow[b]{2}{*}{$\mathbf{p}$} \\
\hline & $\mathbf{N}$ & $\%$ & $\mathbf{N}$ & $\%$ & $\mathbf{N}$ & $\%$ & & \\
\hline Sex & & & & & & & & $<0.001$ \\
\hline Female & 9783 & 55.7 & 6752 & 63.6 & 3036 & 43.7 & $2.22(2.10-2.34)$ & \\
\hline Male & 7783 & 44.3 & 3863 & 36.4 & 3920 & 56.3 & Ref & \\
\hline Marital status & & & & & & & & $<0.001$ \\
\hline Single. Widowed. Divorced & 7597 & 43.3 & 4804 & 45.3 & 2793 & 40.2 & $1.23(1.16-1.31)$ & \\
\hline Other & 9968 & 56.7 & 5807 & 54.7 & 4161 & 59.8 & Ref & \\
\hline Ethnicity & & & & & & & & $<0.001$ \\
\hline Non-white & 12,492 & 71.1 & 7307 & 68.8 & 5185 & 74.5 & $0.75(0.71-0.81)$ & \\
\hline White & 5079 & 28.9 & 3308 & 31.2 & 1771 & 25.5 & Ref & \\
\hline Income $^{a}$ & & & & & & & & 0.001 \\
\hline Less than $\$ 7.83 /$ day & 9620 & 64.8 & 5669 & 63.9 & 3951 & 66.4 & $0.90(0.93-0.98)$ & \\
\hline$\$ 7.83 /$ day & 2588 & 17.5 & 1562 & 17.6 & 1026 & 17.2 & $0.94(0.85-1.05)$ & \\
\hline More than $\$ 7.83 /$ day & 2623 & 17.7 & 1647 & 18.6 & 976 & 16.4 & Ref & \\
\hline Education level & & & & & & & & 0.437 \\
\hline Secondary or lower & 16,187 & 92.3 & 9763 & 92.2 & 6424 & 92.5 & $0.96(0.85-1.07)$ & \\
\hline Upper than secondary & 1352 & 7.7 & 830 & 7.8 & 522 & 7.5 & Ref & \\
\hline Physical inactivity & & & & & & & & $<0.001$ \\
\hline Yes (Low IPAQ-SF score) & 7390 & 42.1 & 5081 & 47.9 & 2309 & 33.2 & $2.01(1.91-2.13)$ & \\
\hline No (Moderate to High IPAQ-SF score) & 10,170 & 57.9 & 5526 & 52.1 & 4644 & 66.8 & Ref & \\
\hline Victim of armed displacement & & & & & & & & $<0.001$ \\
\hline Yes & 3220 & 18.3 & 1850 & 17.4 & 1370 & 19.7 & $0.86(0.80-0.93)$ & \\
\hline No & 14,349 & 81.7 & 8765 & 82.6 & 5584 & 80.3 & Ref & \\
\hline Perceived childhood economic situation & & & & & & & & $<0.001$ \\
\hline Poor & 2901 & 16.6 & 1877 & 17.8 & 1024 & 14.8 & $1.34(1.23-1.47)$ & \\
\hline Fair & 7406 & 42.3 & 4535 & 43.0 & 2871 & 41.4 & $1.16(1.08-1.24)$ & \\
\hline Good & 7182 & 41.1 & 4145 & 39.3 & 3037 & 43.8 & Ref & \\
\hline Functional limitation & & & & & & & & $<0.001$ \\
\hline Yes (Barthel score < 100) & 2791 & 15.9 & 2341 & 22.0 & 450 & 6.5 & $3.76(3.48-4.07)$ & \\
\hline No (Barthel score of 100) & 14,780 & 84.1 & 8274 & 78.0 & 6506 & 93.5 & Ref & \\
\hline Smoking & & & & & & & & 0.807 \\
\hline Former or current smoker & 9094 & 51.8 & 5502 & 51.8 & 3592 & 51.7 & $1.01(0.95-1.07)$ & \\
\hline Nonsmoker & 8473 & 48.2 & 5111 & 48.2 & 3362 & 48.3 & Ref & \\
\hline Area of residence & & & & & & & & $<0.001$ \\
\hline Rural & 4493 & 25.6 & 2383 & 22.5 & 2110 & 30.3 & $0.67(0.63-0.71)$ & \\
\hline Urban & 13,078 & 74.4 & 8232 & 77.5 & 4846 & 69.7 & Ref & \\
\hline Body Mass Index & & & & & & & & $<0.001$ \\
\hline Low BMI $\left(<22 \mathrm{~kg} / \mathrm{m}^{2}\right)$ & 2097 & 15.3 & 1016 & 12.4 & 1081 & 19.6 & $0.76(0.70-0.83)$ & \\
\hline High BMI ('27 kg/m²) & 6155 & 45.0 & 4152 & 50.9 & 2003 & 36.3 & $1.65(1.54-1.77)$ & \\
\hline Normal BMI $\left(22-27 \mathrm{~kg} / \mathrm{m}^{2}\right)$ & 5432 & 39.7 & 2994 & 36.7 & 2438 & 44.1 & Ref & \\
\hline Self-perceived childhood health status & & & & & & & & $<0.001$ \\
\hline Poor or fair & 1836 & 10.5 & 1208 & 11.4 & 628 & 9.0 & $1.30(1.17-1.43)$ & \\
\hline Good & 15,700 & 89.5 & 9382 & 88.6 & 6318 & 91.0 & Ref & \\
\hline Age (Mean (SD)) & $69.2(7.2$ & & $70.0(7$ & & 68.1( & & - & $<0.001$ \\
\hline
\end{tabular}

Table 2. Multimorbidity and individual characteristics. BMI Body Mass Index. ${ }^{a}$ Dollar values for year 2015.

level among the poor, which might not be the same between countries. Moreover, an under-diagnosis or the lag in diagnosis also affects prevalence estimations.

Limitations in our study need to be considered. The self-reported measures of conditions (except depressive symptoms) can underestimate the prevalence; also, effects could be underestimated due to differences between analyzed and excluded individuals, who were significantly older, had a higher proportion of women and had less education and income. Likewise, as secondary data were used, care needs or the severity of the diseases could not be included for the analyses. Unequal weights regarding the type and severity of the conditions are warranted to assess the impact of multimorbidity in the population ${ }^{40}$. 


\begin{tabular}{|l|l|l|r|}
\hline & Adj. OR & 95\% CI & p-value \\
\hline Age (years) & 1.04 & $1.03-1.06$ & $<0.001$ \\
\hline Female sex & 2.27 & $1.84-2.81$ & $<0.001$ \\
\hline Functional limitation & 3.29 & $2.28-4.74$ & $<0.001$ \\
\hline Physical inactivity & 1.38 & $1.13-1.68$ & 0.002 \\
\hline Income of less than $\$ 7.83$ per day $^{\mathrm{a}}$ & 0.72 & $0.55-0.95$ & 0.020 \\
\hline Income of $\$ 7.83$ per day ${ }^{\mathrm{a}}$ & 0.93 & $0.68-1.27$ & 0.651 \\
\hline Rural residence & 0.58 & $0.44-0.77$ & $<0.001$ \\
\hline Non-white ethnicity & 0.73 & $0.58-0.92$ & 0.008 \\
\hline Low BMI $\left(<22 \mathrm{~kg} / \mathrm{m}^{2}\right)$ & 0.73 & $0.55-0.99$ & 0.040 \\
\hline High BMI $\left(27 \mathrm{~kg} / \mathrm{m}^{2}\right)$ & 1.31 & $1.04-1.64$ & 0.021 \\
\hline
\end{tabular}

Table 3. Adjusted associations between individual variables and MM using a multiple logistic stepwise model. BMI Body Mass Index. ${ }^{a}$ Dollar values for year 2015.

\begin{tabular}{|c|c|c|c|}
\hline State & Multimorbidity prevalence & Multidimensional poverty & Infectious diseases mortality rate \\
\hline San Andrés & 74.1 & 8.9 & 12.6 \\
\hline Putumayo & 71.6 & 25.1 & 27.1 \\
\hline Risaralda & 71.1 & 12.5 & 44.2 \\
\hline Bogotá D.C & 71.1 & 4.4 & 23.8 \\
\hline Quindío & 71.1 & 16.2 & 46.2 \\
\hline Antioquia & 69.7 & 17.1 & 35.5 \\
\hline Cundinamarca & 69.3 & 11.5 & 27.6 \\
\hline Valle del Cauca & 68.8 & 13.6 & 39.0 \\
\hline Boyacá & 66.5 & 16.6 & 23.0 \\
\hline Santander & 65.9 & 12.9 & 37.5 \\
\hline Caldas & 65.1 & 15.3 & 29.4 \\
\hline Norte de Santander & 62.6 & 31.5 & 46.1 \\
\hline Cauca & 62.3 & 28.7 & 21.6 \\
\hline Meta & 62.2 & 15.6 & 44.8 \\
\hline Guaviare & 61.7 & 33.5 & 26.4 \\
\hline Nariño & 61.0 & 33.5 & 16.5 \\
\hline Atlántico & 60.3 & 20.1 & 50.6 \\
\hline Bolívar & 59.3 & 32.4 & 37.4 \\
\hline Amazonas & 58.8 & 34.9 & 39.2 \\
\hline Chocó & 58.5 & 45.1 & 36.2 \\
\hline Tolima & 57.8 & 23.5 & 38.8 \\
\hline La Guajira & 56.7 & 51.4 & 30.9 \\
\hline Arauca & 55.7 & 31.8 & 42.6 \\
\hline Casanare & 55.4 & 19.1 & 50.0 \\
\hline Caquetá & 54.6 & 28.7 & 29.5 \\
\hline Córdoba & 54.0 & 36.7 & 38.2 \\
\hline Sucre & 53.8 & 39.7 & 41.1 \\
\hline Vichada & 53.7 & 55.0 & 37.5 \\
\hline Huila & 52.3 & 19.2 & 39.1 \\
\hline Magdalena & 51.8 & 38.6 & 43.3 \\
\hline Cesar & 50.9 & 33.2 & 47.8 \\
\hline Guainía & 44.1 & 65.0 & 51.0 \\
\hline Vaupés & 42.6 & 59.4 & 31.6 \\
\hline
\end{tabular}

Table 4. Multimorbidity prevalence by state and state-level variables.

Considering the above, this paper demonstrates that MM varies between areas regarding mortality of infectious diseases and shows a strong association between MM and poverty in a low-middle income setting. This study found lower levels of MM among individuals in states of high infectious disease mortality rate and in less deprived settings. Further research is needed to better understand the role of deprivation due the scarce number of publications coming from the developing world. Considerable differences in the factors involved in 


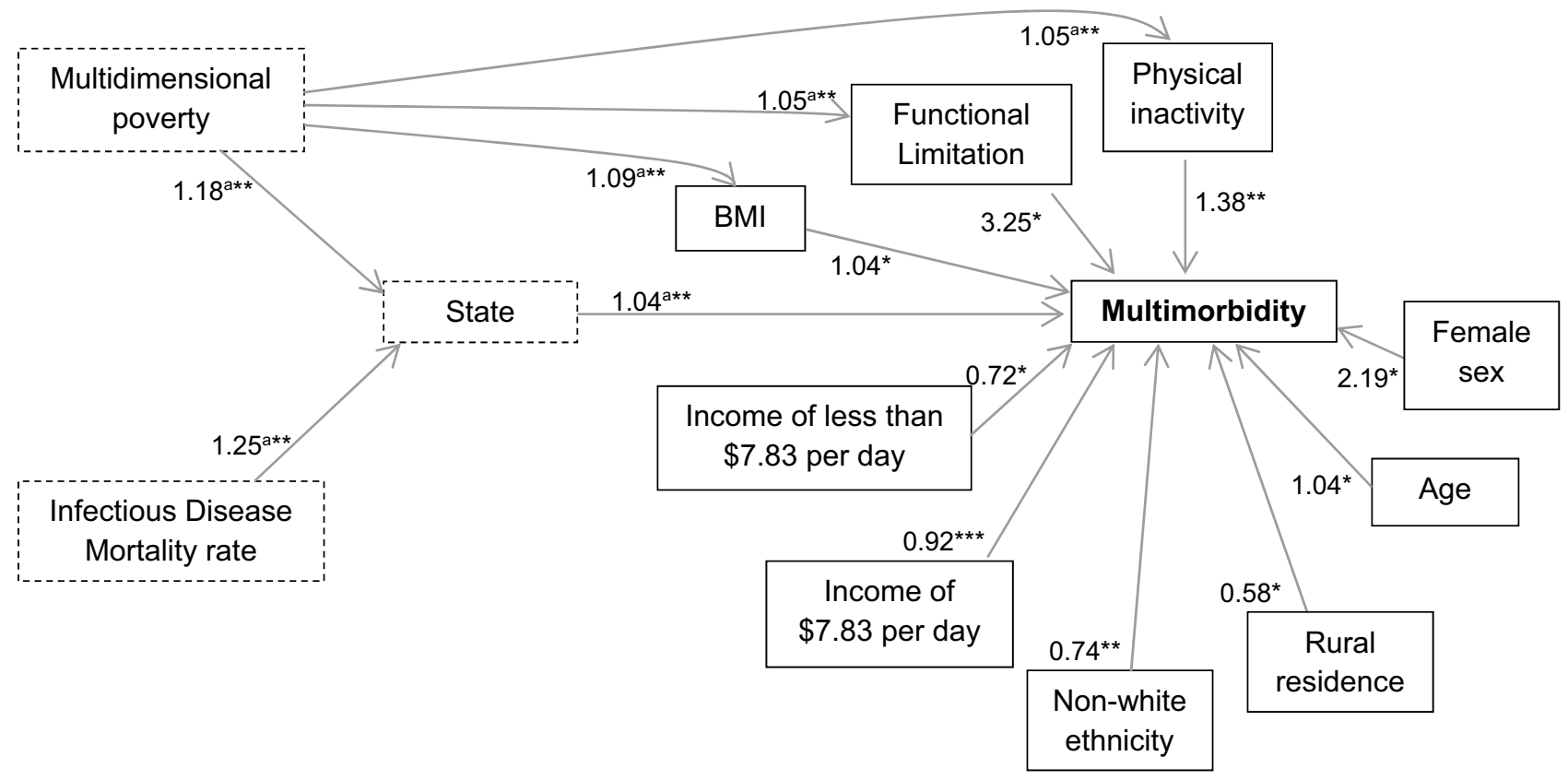

${ }^{a}$ Median Odds Ratio; ${ }^{*}<<0.001 ;{ }^{* *} p<0.05 ;{ }^{* * *} p>0.05$

Figure 1. Final structural equation model (SEM). Odds ratio, median odds ratio and P-values. ${ }^{\mathrm{a} M e d i a n}$ odds ratio; ${ }^{*} \mathrm{p}<0.001 ;{ }^{* *} \mathrm{p}<0.05 ;{ }^{* *} \mathrm{p}>0.05$.

the etiology of MM are expected among high-, middle- and low-income countries regarding availability and prioritization of health services.

\section{Data availability}

The data that support the findings of this study are available from the Colombian Ministry of Health and Social Protection but restrictions apply to the availability of these data, which were used under license for the current study, and so are not publicly available. Data are however available from the authors upon reasonable request and with permission of the Ministry of Health and Social Protection. The datasets regarding group level variables generated during and/or analysed during the current study are available in the National Administrative Department of Statistics repository, https://www.dane.gov.co/index.php/estadisticas-por-tema/pobreza-y-condi ciones-de-vida/pobreza-y-desigualdad/pobreza-monetaria-y-multidimensional-en-colombia-2018\#pobrezapor-departamentos-2018.

Received: 5 April 2021; Accepted: 8 November 2021

Published online: 23 November 2021

\section{References}

1. Xu, X., Mishra, G. D. \& Jones, M. Evidence on multimorbidity from definition to intervention: An overview of systematic reviews. Ageing Res. Rev. 37, 53-68. https://doi.org/10.1016/j.arr.2017.05.003 (2017).

2. World Health Organization. Multimorbidity: Technical Series on Safer Primary Care. https://apps.who.int/iris/bitstream/handle/ 10665/252275/9789241511650-eng.pdf? sequence=1\&isAllowed=y. (Accessed 8 January 2021)

3. Rijken, M., Struckmann, V., van der Heide, I., et al. European Observatory Policy Briefs. in How to improve care for people with multimorbidity in Europe? (Eds. Richardson, E., Van Ginneken, E.) European Observatory on Health Systems and Policies ${ }^{\odot}$ NIVEL and TU Berlin (2017).

4. Macinko, J., Andrade, F. C. D., Nunes, B. P. \& Guanais, F. C. Primary care and multimorbidity in six Latin American and Caribbean countries. Rev. Panam. Salud. Publica. 43, e8. https://doi.org/10.26633/rpsp.2019.8 (2019).

5. Alfonso-Sierra, E., Carabalí, A.A., Torres, J.B., Castro, M.L.L., Ramírez, A.P., Velásquez, L.U. Situación de Multimorbilidad en Colombia 2012-2016 (2016).

6. Afshar, S., Roderick, P. J., Kowal, P., Dimitrov, B. D. \& Hill, A. G. Multimorbidity and the inequalities of global ageing: A crosssectional study of 28 countries using the World Health Surveys. BMC Public Health 15, 776. https://doi.org/10.1186/s12889-0152008-7 (2015).

7. Banerjee, S. Multimorbidity-older adults need health care that can count past one. Lancet 385(9968), 587-589. https://doi.org/ 10.1016/s0140-6736(14)61596-8 (2015).

8. Aarts, S. et al. The effect of multimorbidity on health related functioning: Temporary or persistent? Results from a longitudinal cohort study. J. Psychosom. Res. 73(3), 211-217. https://doi.org/10.1016/j.jpsychores.2012.05.014 (2012).

9. Bao, J., Chua, K. C., Prina, M. \& Prince, M. Multimorbidity and care dependence in older adults: A longitudinal analysis of findings from the 10/66 study. BMC Public Health 19(1), 585. https://doi.org/10.1186/s12889-019-6961-4 (2019).

10. Marengoni, A. et al. Aging with multimorbidity: A systematic review of the literature. Ageing Res. Rev. 10(4), 430-439. https://doi. org/10.1016/j.arr.2011.03.003 (2011). 
11. Wolff, J. L., Starfield, B. \& Anderson, G. Prevalence, expenditures, and complications of multiple chronic conditions in the elderly. Arch. Intern. Med. 162(20), 2269-2276 (2002).

12. Rivera-Almaraz, A. et al. Disability, quality of life and all-cause mortality in older Mexican adults: Association with multimorbidity and frailty. BMC Geriatr. 18(1), 236. https://doi.org/10.1186/s12877-018-0928-7 (2018).

13. Bahler, C., Huber, C. A., Brungger, B. \& Reich, O. Multimorbidity, health care utilization and costs in an elderly communitydwelling population: A claims data based observational study. BMC Health Serv. Res. 15, 23. https://doi.org/10.1186/s12913-0150698-2 (2015).

14. St John, P. D., Tyas, S. L., Menec, V. \& Tate, R. Multimorbidity, disability, and mortality in community-dwelling older adults. Can. Fam. Physician. 60(5), e272-e280 (2014).

15. Kristensen, K., König, H.-H. \& Hajek, A. The association of multimorbidity, loneliness, social exclusion and network size: Findings from the population-based German Ageing Survey. BMC Public Health 19(1), 1383. https://doi.org/10.1186/s12889-019-7741-x (2019).

16. Pathirana, T. I. \& Jackson, C. A. Socioeconomic status and multimorbidity: A systematic review and meta-analysis. Aust. N. Z. J. Public Health. 42(2), 186-194. https://doi.org/10.1111/1753-6405.12762 (2018).

17. Gontijo Guerra, S., Berbiche, D. \& Vasiliadis, H. M. Measuring multimorbidity in older adults: Comparing different data sources. BMC Geriatr. 19(1), 166. https://doi.org/10.1186/s12877-019-1173-4 (2019).

18. Schiøtz, M. L., Stockmarr, A., Høst, D., Glümer, C. \& Frølich, A. Social disparities in the prevalence of multimorbidity-A registerbased population study. BMC Public Health 17(1), 422. https://doi.org/10.1186/s12889-017-4314-8 (2017).

19. Tucker-Seeley, R. D., Li, Y., Sorensen, G. \& Subramanian, S. V. Lifecourse socioeconomic circumstances and multimorbidity among older adults. BMC Public Health 11, 313. https://doi.org/10.1186/1471-2458-11-313 (2011).

20. Ataguba, J. E. Inequalities in multimorbidity in South Africa. Int. J. Equity Health. 12, 64. https://doi.org/10.1186/1475-9276-12-64 (2013).

21. Barnett, K. et al. Epidemiology of multimorbidity and implications for health care, research, and medical education: A crosssectional study. Lancet 380(9836), 37-43. https://doi.org/10.1016/s0140-6736(12)60240-2 (2012).

22. Salisbury, C., Johnson, L., Purdy, S., Valderas, J. M. \& Montgomery, A. A. Epidemiology and impact of multimorbidity in primary care: A retrospective cohort study. Br. J. Gen. Pract. 61(582), e12-21. https://doi.org/10.3399/bjgp11X548929 (2011).

23. European Centre for Disease Prevention and Control. Health Inequalities, The Financial Crisis, and Infectious Disease in Europe (ECDC, 2013).

24. Pawelec, G. Age and immunity: What is "immunosenescence"?. Exp. Gerontol. 105, 4-9. https://doi.org/10.1016/j.exger.2017.10. 024 (2018).

25. Gomez, F., Corchuelo, J., Curcio, C. L., Calzada, M. T. \& Mendez, F. SABE Colombia: Survey on health, well-being, and aging in colombia-study design and protocol. Curr. Gerontol. Geriatr. Res. 2016, 7910205. https://doi.org/10.1155/2016/7910205 (2016).

26. Sheik, J. \& Yesavage, J. Geriatric Depression Scale: Recent Evidence and Development of a Shorter Version. Clinical Gerontology: A Guide to Assessment and Intervention 165-173 (The Hawthorne Press, 1986).

27. Alexandre Tda, S. et al. Gender differences in incidence and determinants of disability in activities of daily living among elderly individuals: SABE study. Arch. Gerontol. Geriatr. 55(2), 431-437. https://doi.org/10.1016/j.archger.2012.04.001 (2012).

28. Sainsbury, A., Seebass, G., Bansal, A. \& Young, J. B. Reliability of the Barthel Index when used with older people. Age Ageing. 34(3), 228-232. https://doi.org/10.1093/ageing/afio63 (2005).

29. Lipschitz, D. A. Screening for nutritional status in the elderly. Prim. Care. 21(1), 55-67 (1994).

30. IPAQ scoring protocol-International Physical Activity Questionnaire (2016)

31. Angulo R, Díaz Y, Pardo R. Índice de Pobreza Multidimensional para Colombia. 2011. https://EconPapers.repec.org/RePEc:col: 000118:009228. (Accessed 1 December 2020)

32. Departamento Administrativo Nacional de Estadística. Pobreza Monetaria y Multidimensional en Colombia 2018. https://www. dane.gov.co/index.php/estadisticas-por-tema/pobreza-y-condiciones-de-vida/pobreza-y-desigualdad/pobreza-monetaria-y-multi dimensional-en-colombia-2018\#pobreza-por-departamentos-2018. (Accessed 5 December 2020)

33. Ministerio de Salud y Protección Social. Análisis de Situación de Salud (ASIS) Colombia, 2017. https://www.minsalud.gov.co/ sites/rid/Lists/BibliotecaDigital/RIDE/VS/ED/PSP/asis-nacional-2017.pdf. (Accessed 1 December 2020)

34. Alkire, S. \& Santos, M. E. Measuring acute poverty in the developing world: Robustness and scope of the multidimensional poverty index. World Dev. 59, 251-274 (2014).

35. Merlo, J. et al. A brief conceptual tutorial of multilevel analysis in social epidemiology: Using measures of clustering in multilevel logistic regression to investigate contextual phenomena. J. Epidemiol. Community Health. 60(4), 290-297. https://doi.org/10.1136/ jech.2004.029454 (2006).

36. Pinilla-Roncancio, M. et al. Multidimensional poverty and disability: A case control study in India, Cameroon, and Guatemala. SSM Popul. Health. 11, 100591. https://doi.org/10.1016/j.ssmph.2020.100591 (2020).

37. Amaral, T. L. M. et al. Multimorbidity, depression and quality of life among elderly people assisted in the Family Health Strategy in Senador Guiomard, Acre, Brazil. Cien. Saude. Colet. 23(9), 3077-3084. https://doi.org/10.1590/1413-81232018239.22532016 (2018) (Multimorbidade, depressão e qualidade de vida em idosos atendidos pela Estratégia de Saúde da Família em Senador Guiomard, Acre, Brasil).

38. Olivares, D. E. et al. Risk factors for chronic diseases and multimorbidity in a primary care context of Central Argentina: A webbased interactive and cross-sectional study. Int. J. Environ. Res. Public Health. https://doi.org/10.3390/ijerph14030251 (2017).

39. Kushitor, M. K. \& Boatemaa, S. The double burden of disease and the challenge of health access: Evidence from Access, Bottlenecks, Cost and Equity facility survey in Ghana. PLoS ONE 13(3), e0194677. https://doi.org/10.1371/journal.pone.0194677 (2018).

40. Zhao, Y. et al. Physical multimorbidity, health service use, and catastrophic health expenditure by socioeconomic groups in China: An analysis of population-based panel data. Lancet Glob. Health. 8(6), e840-e849. https://doi.org/10.1016/s2214-109x(20)30127-3 (2020).

41. Cuthbertson, C. C. et al. Socioeconomic status and access to care and the incidence of a heart failure diagnosis in the inpatient and outpatient settings. Ann. Epidemiol. 28(6), 350-355. https://doi.org/10.1016/j.annepidem.2018.04.003 (2018).

42. Kunna, R., San Sebastian, M. \& Stewart Williams, J. Measurement and decomposition of socioeconomic inequality in single and multimorbidity in older adults in China and Ghana: Results from the WHO study on global AGEing and adult health (SAGE). Int. J. Equity Health. 16(1), 79. https://doi.org/10.1186/s12939-017-0578-y (2017).

43. Foguet-Boreu, Q. et al. Impact of multimorbidity: Acute morbidity, area of residency and use of health services across the life span in a region of south Europe. BMC Fam. Pract. 15, 55. https://doi.org/10.1186/1471-2296-15-55 (2014).

\section{Author contributions}

S.M.B. and J.M.M. conceived the study and analyzed the data. S.M.B. wrote the first and successive drafts of the manuscript, J.M.M. and W.J.A.G. contributed to the writing of the manuscript. All authors critically revised the manuscript for important intellectual content and contributed to the interpretation of results. All authors have given final approval of the version to be published. 


\section{Funding}

This research did not receive any specific grant from funding agencies in the public, commercial, or not-forprofit sectors.

\section{Competing interests}

The authors declare no competing interests.

\section{Additional information}

Correspondence and requests for materials should be addressed to S.M.B.

Reprints and permissions information is available at www.nature.com/reprints.

Publisher's note Springer Nature remains neutral with regard to jurisdictional claims in published maps and institutional affiliations.

(c) (i) Open Access This article is licensed under a Creative Commons Attribution 4.0 International License, which permits use, sharing, adaptation, distribution and reproduction in any medium or format, as long as you give appropriate credit to the original author(s) and the source, provide a link to the Creative Commons licence, and indicate if changes were made. The images or other third party material in this article are included in the article's Creative Commons licence, unless indicated otherwise in a credit line to the material. If material is not included in the article's Creative Commons licence and your intended use is not permitted by statutory regulation or exceeds the permitted use, you will need to obtain permission directly from the copyright holder. To view a copy of this licence, visit http://creativecommons.org/licenses/by/4.0/.

(C) The Author(s) 2021 